Journal of Qualitative Criminal Justice \& Criminology • Pre-Issue Pubs

\title{
Hate Exhaustion, \\ Emotional Support, and Desistance From White Supremacist Groups
}

\author{
April Celeste Gould ${ }^{1}$ \\ ${ }^{1}$ University of California, Riverside
}

Published on: May 24, 2021

License: Creative Commons Attribution 4.0 International License (CC-BY 4.0). 


\section{ABSTRACT}

This study examines how and why people join, participate in, and leave White supremacist terrorist (WST) groups. In-depth life history interviews and biographic timelines of former White supremacists in the United States and Canada were collected. Findings indicate that former members' decisions to engage and desist from WST groups are greatly influenced by their experiences of emotional support-or lack thereof. Participants lacked emotional support prior to joining WST and the emotional support they received from group membership was toxic. Participants exited WST because they experienced hate exhaustion and were willing to sacrifice all or most of their emotional support to alleviate it. This research contributes to the theoretical understandings of emotional support's influence in engagement and disengagement from WST by speaking to Snow and Machalek's (1983) characteristics of converts, the Identity Theory of Desistance (Paternoster and Bushway 2009), and Latif et al.'s (2018) WST emotional dynamics models. Moreover, this study asks if desistance is similar to burnout and if radicalization is similar to conversion. This work has practical implications regarding the prevention of initial involvement, the development of interventions to disrupt these activities, and the facilitation of disengagement from WST groups.

\section{Introduction}

The United States and Canada have extensive histories of White supremacist terror. Although White supremacist groups are not always designated as terror groups, Simi (2010) argues that there is no meaningful distinction, and the lethality of events like the 1995 Oklahoma City bombing and the 2017 "Unite the Right" rally in Charlottesville, Virginia underscore this notion. White supremacist terrorism (WST) is "violence perpetrated by organized groups against racial [and other] minorities in the pursuit of white and Aryan supremacist agendas" (Blee, 2008, p. 274). To be clear, this definition does not rule out lone actor terrorists; regardless of if a terrorist commits an attack with a group or individually, to be considered a WST member, they must be affiliated with an organized hate group that justifies or endorses violence on behalf of the superiority of the White race. WST differs from general white supremacism in the United States-underlying attitudes and social structures which value whiteness above non-whiteness-in that it is more overt, organized, and violent.

Systems of support are essential to understand engagement and disengagement from violent extremism-including WST-given that social support can both increase 
criminal behavior by pulling people in (Brezina \& Andia 2018; Cullen, 1994) and prompt exits among members of terrorist groups, cults, street gangs, and mainstream religious movements (Windisch et al., 2016). Emotional support can act to either attract members to join violent groups or serve to pull them out when found elsewhere. Social support is inherently linked to the Identity Theory of Desistance (Patternoster \& Bushway, 2009) because it recognizes that, "that identity change must come before prosocial opportunities can arrive and be successfully used, and that desistance can occur even in the absence of conventional turning points such as good jobs or partnerships" (Bachman et al. 2016b, p. 181).

One form of social support is emotional support, which refers to real or perceived actions made by others that assist a person in managing their feelings and relationships. Scholars have also employed emotional support, "to refer to the provision of empathy, caring, trust, and concern" (Jayaratine \& Chess, 1984, p. 146). Racists are more likely to struggle with social support and have more psychological struggles than their tolerant counterparts throughout their lives (Hightower, 1997). Social support, however, is not exclusively beneficial for those who receive it. Negative consequences can originate from social support when relationships are overly demanding, full of conflicts, and/or overly controlling (House et al., 1988). Hereafter, this paper refers to such detrimental emotional support as "toxic."

Although research shows an array of factors that facilitate or impede the process through which individuals depart from extremist groups (Horgan, 2009; Bubolz \& Simi, 2015; Kruglanksi et al., 2014), little is known about the role that emotional support, plays in people's engagement, involvement, and disengagement from white supremacist groups. Building off the emotional dynamics models for former white supremacists (see Latif et al., 2018) and Colvin and colleagues' (2002) concept of differential social support, this study investigates the importance of emotional support and its health consequences on formers' engagement, involvement, and disengagement from WST. Of note, throughout this text participants are referred to as formers because that is how they identify themselves and asked that I refer to them.

It should be noted that many of the issues touched upon in this paper have origins in the gang desistance literature. Understanding desistance from a lifecourse perspective was made famous by Sampson and Laub (2003) and has subsequently been applied to gang desistance specifically (Moule et al., 2012). Carson and Vecchio (2015, p. 258) have also brought attention to "the severing of social and/or emotional ties to the gang" as a challenge for desisters, and thus many scholars categorize desisters in 
terms of how many ties remain (Decker and Lauritsen 2002; Pyrooz \& Decker, 2011; Pyrooz et al., 2012). Similarly, Densley and Pyrooz (2019, pp. 38-39) contend that social ties which embed members in gang involvement, are paramount in understanding desistance, "De-identification as a gang member, we hold, occurs during the disengagement process but is neither a necessary or a sufficient condition that must be met to observe declining or trivial levels of embeddedness." In sum, scholars have found that emotional ties, social capital, and social networks are relevant in desistance from gangs (Roman et al., 2021; Pyrooz et al., 2010; Moule et al., 2012). Increasingly, scholars have begun exploring the overlap between gang desistance and WST (Reid \& Valasik, 2020; Simi \& Futrell, 2015).

This research applies the Snow and Machalek's (1983) characteristics of converts to better understand how people engage and disengage from WST. As conceptualized, those who convert to a new religion, or in this case, a radical ideology, undergo a process of biographical reconstruction, adoption of a master attribution scheme, suspension of analogical reasoning, and embracement of a master role (Snow \& Machalek, 1983). Former WST members are likely to have experienced this conversion process during their entrance into WST, as their involvement in violent extremism is a "totalizing commitment" with destructive effects (Simi et al., 2017).

The Identity Theory of Desistance (ITD) (Paternoster \& Bushway, 2009) argues that people refrain from criminal activity when they have internal transformation in their sense of self that create a desire for a pro-social identity (Paternoster et al., 2016; Aresti et al., 2010; Bachman et al., 2016a). This theory has received empirical support in its utility for drug-involved offenders (Bachman et al., 2016a; Bachman et al., 2016b; Paternoster et al., 2016), male property offenders (LeBel et al., 2008), pregnant substance-using women and mothers (Stone 2016), and terrorists (Raets, 2017). Similar to Maruna's (2001) 'Making Good' framework, the Identity Theory of Desistance argues that desistance comes from within and needs to be supported by opportunities for pro-social engagement to cultivate pro-social identities (Paternoster and Bushway 2009; Paternoster et al., 2016). The identity change process culminates in a fear of one's self that builds "when perceived failures and dissatisfactions within different domains of life become connected and when current failures become linked with anticipated future failures" (Paternoster \& Bushway, 2009, p. 1105). Applying this theory to desistance from WST is appropriate, as Simi and colleagues (2017) assert membership in WST is an "addiction," and argue that leaving WST requires a rejection of one's identity as a member, disassociation from social networks, and abandoning WST social support. This research aims to determine if Snow and Machalek's (1983) 
process of conversion applies to participants' experiences engaging in WST. This research also will explore if Paternoster and Bushway's (2009) Identity Theory of Desistance is applicable for former WST members. At its core, this research is interested in participants' experiences of coercion and emotional support before, during, and after exit from WST groups. Finally, this study is interested in participants' experiences of emotional support as they may inform Latif et al.'s emotional dynamics models of white supremacist groups.

This study unearths specific experiences of emotional support that formers utilize throughout their lives, which further advance the literature on white supremacist groups and understandings of the emotional dynamics employed in them, by including the roles of emotional support and hate exhaustion in current models (Latif et al., 2018). Ultimately, the aim of this work is to identify the mechanisms underlying emotional support in the lives of those who have left WST so as to inform interventions that prevent people from joining similar violent extremist groups and to help those who wish to exit violent extremism transition out of hate more easily.

\section{The relevance of emotional dynamics in WST}

\section{Previous scholarship}

White supremacist terror groups thrive not only on shared ideologies and political aims, but on unique group dynamics. In fact, WST groups are strengthened by the shared anger, hate, and violence of their members because the adrenaline associated with WST activities cultivates a shared energy that bonds the group (Latif et al., 2018). Thus, the emotional dynamics of WST groups produce heightened and unique experiences of social support from within a toxic hate group. The rush of excitement and power that members feel during involvement is often a main reason they stay involved, and for many, a reason they re-engage after leaving. Latif and colleagues (2018) conceptualize residual emotions as the lingering, sometimes nostalgic, attachments that people have to their group after they have exited. Residual emotions can lead people to maintain ties with the white supremacist movement and sometimes re-enter the group. Moreover, the shared emotional bonds that the WST fosters makes the group emotionally resilient to outgroup conflict as well as differences between members (Latif et al., 2018).

Although Latif and colleagues' (2018) work focuses on the emotional dynamics of WST groups, emotional dynamics are salient across social movements. Collins' (2004) theory of interaction ritual chains explains how rituals galvanize groups by creating 
shared foci, group-specific symbols, and group emotions that draw people into a group and reinforce their continued involvement. Collins (2004) argues that interaction rituals primarily create emotional energy, group symbols, group-specific morality, and group solidarity. These outcomes keep people involved in their groups, and when these outcomes break down, the group begins to dismantle. Collins (2004) explicated how the emotional dynamics of groups produce unity. He explains that emotions such as outrage, anger, and fear bring people to the group initially and create "distinctively collective emotions, the feelings of solidarity, enthusiasm, and morality" In terms of former WSTs, giving up these strong collective emotions is undoubtedly stressful and challenging (Collins 2004, p. 29).

As a result, I apply this framework in my analysis of former WSTs in this study. I argue that emotional support is a mediating factor that when not present, led participants into WST, and when present and toxic, persuaded participants to exit WST. Moreover, after finding present and positive emotional support, participants were able to stay out of WST movements and create happy lives for themselves.

\section{Coercion and emotional support}

The roles of social support and coercion on criminal activity are explicated in the theory of differential social support and coercion (Colvin et al., 2002). Social support consists of words and behaviors people express to one another to help meet their emotional, informational, and instrumental needs. Coercion, on the other hand, is defined as physical attacks, negative commands, critical remarks, teasing, humiliation, whining, yelling, and threats. Colvin and colleagues (2002) were especially interested in the outcomes of individuals who experienced erratic versus consistent coercion and social support, and whether these result in criminal or prosocial behavior. Overall, Colvin and colleagues (2002) found that coercion can sometimes lead to law-abiding behaviors, and social support can sometimes lead to criminal engagement. The authors explain that consistent coercion-for example, constant supervision in a supermax prison-is argued to produce lawful compliance; moreover, implicit coercion via providers of social support, "may have its best crime-controlling effect" (Colvin et al., 2002 , p. 23). Thus, it only follows that emotional support is also differential in this manner. While Simi and colleagues (2017) underscore the significance of social ties, social friction, and shared emotions in explaining participation in WST, they neglect the role of emotional support in this process. Similarly, research identifies various factors that facilitate or impede departures from extremist groups (Bubolz \& Simi, 
2015; Horgan, 2009; Kruglanski et al., 2014), yet little is known about how one of the primary types of social support-emotional support-impacts such transitions.

\section{Formers as converts}

Snow and Machalek's (1983) characteristics of converts as a social type were used to analyze entrance and exit from WST as conversion. These included biographical reconstruction, adoption of a master attribution scheme, suspension of analogical reasoning, and embracement of a master role. Through the creation of biographical reconstructions, Snow and Machalek (1983), explained that converts often reject their pre-conversion lives because they see themselves as not living with truth, and they are grateful for their conversion for showing them the egregiousness of their pasts. Moreover, this rejection extends to social ties that do not align with their newfound beliefs.

Snow and Machalek (1983, p. 270) defined the adoption of a master attribution scheme as "one causal scheme or vocabulary of motives informs all causal attributions." WST ideologies employed by formers during their involvement were analyzed through this lens. Snow and Machalek's (1983, p. 275) third component of conversion is suspension of analogical reasoning: "allow[ing] converts to assign incomparable value to their world view. By removing other belief systems from the status of eligible competition, a virtually impermeable boundary is established around the convert's world view." Finally, Snow and Machalek (1983, p. 278) found that converts take on master roles, meaning that their role as a convert becomes their primary identity, "For the convert, such role identities as father, mother, brother, sister, student, and so on pale in comparison to the role identity of the convert." Participants echoed this concept when they reported the "totalizing commitment" (Simi et al., 2017) that WST requires.

\section{Defining hate exhaustion}

The notion of hate exhaustion-emotional exhaustion from living a life of hatred and violence-is similar to concepts usually found within labor studies: emotional labor and burnout. Emotional labor is the idea that work involving the expression and/or intense managing of emotions is exchanged for compensation-financial or otherwise (Jeung et al., 2018). In traditional studies of employment, the literature substantiates that emotional labor contributes negatively to employee health outcomes (Jeung et al., 2018). Burnout has been defined by service industry research as "a state of emotional, mental, and physical exhaustion caused by excessive and prolonged stress" (Jeung et 
al., 2018, p. 188). Emotional labor, if not coped with sufficiently, can lead to burnout, and negative health outcomes. This paper uses the term "hate exhaustion" to refer to the burnout former white supremacists experienced from the emotional labor associated with the hate they were expected to maintain, and the differential emotional support they received during their involvement in WST. This concept refers specifically to the emotional labor of being a member of an organized hate group, and the toll it takes on a person long-term.

\section{The present study}

This research examines how emotional support operates among former WSTs, an understudied population, throughout their "deviant careers" (Becker, 1963). This research was informed by the emotional dynamics model for former white supremacists (see Latif et al., 2018), which explains that individual emotional experiences invigorate and destroy WST groups by igniting and extinguishing the emotional energy of the collective. Citing the work of Collins (2001, p. 2004), the authors explain that WST groups thrive on emotional energy-even if this energy is produced by violence and hatred; however, as members feel shame, disillusionment, and fatigue, the energy decreases and the group splinters (Latif et al., 2028). This study explores the various types of social support and the consequences of each as they impact trajectories in white supremacist terrorist groups. In this endeavor, I utilize life history and lifeline methodologies to examine one's social support prior to involvement, during involvement, during disengagement, and post disengagement. Gramling and Carr (2004, p. 208) explain that life history and lifeline (i.e., biographical timeline) methods have been used extensively in criminology, medical sociology, and clinical health settings to understand the temporal sequence of life events and to link "experiences to subsequent actions and theoretical perspectives and personal experiences."

\section{Methods}

\section{Sample}

The twelve participants who were interviewed for this research were recruited several ways. First, using a strategy also employed by Bubolz and Simi (2015), a list of people covered in media outlets as being former white supremacists was compiled and they were approached directly using public contact information. Second, snowball sampling was used, as participants were asked to recommend others who might be interested in participating and met the inclusion criteria. Third, I contacted programs that help 
people leave violent extremist groups and asked them if they were willing to distribute my recruitment flyer and contact information to their clients. To be eligible for participation, participants must have identified as former members of WST groups, be at least 18 years of age, be able to consent to study participation, be fluent in spoken English, and live in the United States or Canada. The sample consists of twelve former white supremacists. WST groups include but are not limited to the Ku Klux Klan, neoNazis, racist skinhead groups, The Order, Combat 18, and the National Socialist Movement. Six participants were women and six were men. Participants were born between 1964 and 1990. Participants had diverse experiences with the number of WST groups they were involved in, the duration of their involvement, their roles while involved, and their ages of entry and exit. Participants were asked if they identified as poor, working, middle, or upper class, during their childhoods, adolescence, early adulthood, and present. Although this measure may not accurately capture their exact socioeconomic standing sociologically, it does capture how they identified socioeconomically at different times in their lives. Thus, this is more of a relative measure than an absolute measure which would require much more information (e.g., intergenerational wealth, income, debt, occupational prestige, etc.). Table 1 summarizes the demographic characteristics of the sample and summarizes participants' WST involvement information.

Table 1. Participant demographics and WST involvement

\begin{tabular}{|l|l|l|l|}
\hline & Minimum & Maximum & Average/Mode \\
\hline Year of birth & 1964 & 1990 & 1973 \\
\hline Employed & No & Yes & Yes \\
\hline Current SES & Working class & Upper class & Middle class \\
\hline Childhood SES & Poor & Upper class & Middle class \\
\hline Education & $<$ High School & Master's degree & Some college \\
\hline Relationship status & Single & Married & Married \\
\hline Children & No & Yes & Yes \\
\hline
\end{tabular}




\begin{tabular}{|c|c|c|c|}
\hline $\begin{array}{l}\text { Ever incarcerated/or } \\
\text { convicted }\end{array}$ & No & Yes & Yes \\
\hline Year of birth & 1964 & 1990 & 1973 \\
\hline Employed & No & Yes & Yes \\
\hline $\begin{array}{l}\text { Number of WST } \\
\text { groups: }\end{array}$ & 1 & 4 & 3 \\
\hline - Age of entry (years): & 5 & 40 & 18 \\
\hline - Age of exit (years): & 19 & 47 & 30 \\
\hline \multirow{2}{*}{$\begin{array}{l}\text { - Duration of } \\
\text { involvement (years): }\end{array}$} & 3.5 & 27.5 & 12 \\
\hline & Yes & No & Not applicable \\
\hline Male & 6 & 6 & \\
\hline $\begin{array}{l}\text { Current partner ever } \\
\text { involved in WST }\end{array}$ & 2 & 8 & 2 \\
\hline $\begin{array}{l}\text { Anti-racist } \\
\text { activism/intervention } \\
\text { work }\end{array}$ & 11 & 1 & \\
\hline \multicolumn{4}{|l|}{$\begin{array}{l}\text { Roles during } \\
\text { involvement* }\end{array}$} \\
\hline - General member & 1 & & \\
\hline - Recruiter & 5 & & \\
\hline - Propagandist & 3 & & \\
\hline - Security & 1 & & \\
\hline - Leader or cofounder & 6 & & \\
\hline
\end{tabular}

Note: '*' denotes some participants had multiple roles during their involvement in WST. 


\section{Data collection and analysis}

This research consisted of semi-structured audio recorded two hour interviews. Participants were asked demographic questions, as well as about their life histories (who they were before, during, and after violent extremism), their experiences of social support and coercion, and their experiences of leaving violent extremist groups. In exchange for participation, respondents received a $\$ 20.00$ gift card. After each interview, the researcher completed a timeline based upon the interview and sent it to each participant for verification of accuracy. All timeline modification requests were honored. Data collection began in June of 2019.

My interview guide of semi-structured in-depth questions asked participants about themselves and their experiences holistically, with the concept of intersectionality in mind. Thus, the researcher was mindful that participants had multiple identities-as partners, parents, siblings, friends, employees, and activists-outside of their identities as former white supremacists. Following Blee's (2002) work, participants were asked to let the researcher know of places that they were comfortable being interviewed. However, the majority (8) of the interviews were conducted over the phone because of distance, time, and financial considerations of the researcher. The only in-person interview was held in a coffee shop in the participant's hometown. Three interviews were conducted via online video.

Each interview was transcribed, and any identifiable information was altered to protect participants' confidentiality. For example, cities were changed to regions, and all names were changed to pseudonyms. Moreover, transcripts were first generated verbatim and then unnecessary "ummms" and "likes" were removed, but the original sentiments were intact. Transcriptions were analyzed two ways using Dedoose qualitative analytic software. First, the transcripts were theoretically coded according to the tenants of Latif and colleagues' (2018) emotional dynamics models, Snow and Machalek's (1983) characteristics of converts, Colvin and colleagues' (2002) model of differential support and coercion, and Paternoster and Bushway's (2009) Identity Theory of Desistance. In particular, special attention was paid to the following concepts: emotional resilience; identity salience and stability; residual emotion; coercion; and social support. Next, open or grounded theory was employed to enable me to identify nuances and patterns in the data that may not have been addressed by the study's two theoretical frameworks. 


\section{Differential emotional support in the lives of formers}

The data from study participants supports research which establishes that exiting violent extremism is a process in and of itself, which seldom occurs instantaneously (Horgan, 2009; Bubloz \& Simi, 2015; Kruglanksi et al., 2014). Figure 1 shows the key findings of the role of differential emotional support through the lives of former WSTs and is organized into four broad categories: before involvement, during involvement, exiting, and after exit. These categories illuminate how the three types of social support varied across the life course stages, which additionally align with movement trajectories. Next, I provide in-depth analysis of participants' experiences with social support as it links to their involvement with WST groups.

Figure 1. Former White supremacists emotional support model

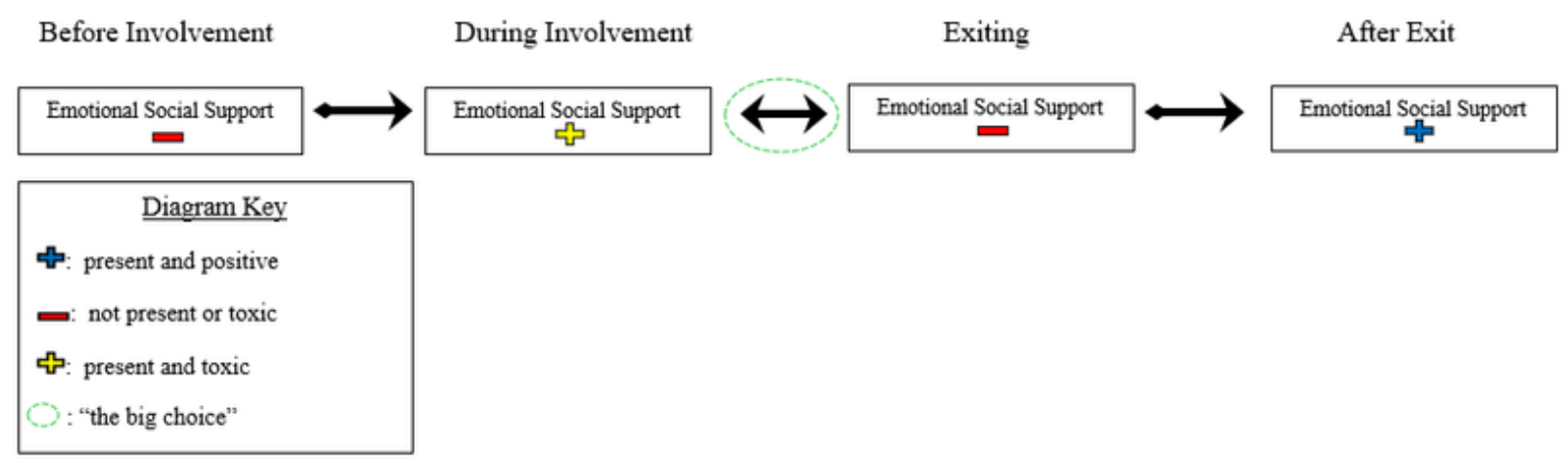

\section{Before involvement: Privileged backgrounds}

As Figure 1 shows, participants described lacking emotional social support prior to engaging in WST, and this desire often fueled participants' entry into white supremacy. These recognized deficits led them to seek out emotional support from people who shared this anger, a key feature of WST groups. This lack of emotional support indeed made them susceptible to WST involvement. For example, some participants explained that they lacked emotional social support prior to engaging in WST because they lost a core relationship that provided them with that support (e.g., death of a parent or close friend). Others, however, felt that they did not have anyone they could confide in until they met members of WST groups. Finally, some recognized efforts made by others to emotionally support them, but they were unsatisfied with them. 
Several participants emphasized that there is a prevalent misconception that people who join WST are poor, uneducated, and come from broken homes. Yet they argued this characterization was only accurate for a minority of white supremacists. "Michael" articulated this sentiment when he explained:

I really can't think of anything particularly bad at all from growing up. I know the narrative too, with a lot of the people and a lot of the stories that are out there is these abused kids coming from broken homes and things like that and there is those people in the movement. But that is not the most common story from my experience and then there is those stories, but I would not say that the majority. I'd say that's more like 10 to $20 \%$ maybe.

As Table 1 demonstrates, ten out of the twelve formers were not raised in poverty but instead came from working- $(n=3)$, middle- $(n=4)$, and upper-class $(n=3)$ backgrounds (one participant's childhood SES was unknown). Prior to involvement, eleven participants reported a lack of emotional support from parents and family members. Despite growing up in suburban neighborhoods, taking family vacations, and participating in extracurricular activities, such as gymnastics, music lessons and wood working they did not feel that their emotional needs in their relationships were met.. This lack of emotional social support among the participants from varied SES familial backgrounds often stemmed from time-strapped parents busy working multiple jobs, or from overprotective parents hoping to shield them from illness, injury, or negative influences. Although, overprotective parents seem like positive, present emotional support, the participants who experienced it explained that they were seldom allowed to leave their childhood homes and interact with anyone other than their parents. Moreover, their parents often lacked emotional vocabulary; thus, when participants experienced challenges, they did not feel they could express their emotions to their parents or anyone else. "Emma," a participant who had a wealthy upbringing, provided an account that exemplified a deficit in emotional support prior to her joining the $\mathrm{Ku}$ Klux Klan:

It's terrible to say but that was one of the dysfunctional things is they always bought you stuff. ... It's kind of like very dysfunctional. I always had whatever I wanted handed to me. No concept of money. ... My grandmother was around, but once again, a lot of it was just money, "like here." I don't know that that's really... when you're young and dumb it's fun but it kind of becomes like a substitute. I think that's common in families where there's money. It's actually, “Okay, I gave 
you something" that kind of gets equated with love. Now I kind of think maybe time would have been a little better.

Although wealthy, she had been raised without a father and by a negligent mother. In Emma's case, she found her first consistent source of emotional support when she joined the Klan, which provided her with emotional social support despite it being a negative experience overall. She explained that her experiences with the Klan seemed to have a prominent quality of normalcy with an "undercurrent" of hate that served as an ever-present subtext. "Stephanie," a former neo-Nazi, described her upbringing as, "upwardly mobile middle-class" and explained that although well-off, emotional support was absent, which became especially painful after she was raped as a young teenager:

I didn't feel like I really belonged in my family. I really felt like the black sheep in my family. They were supportive, though. They were involved with my education and extracurricular activities and stuff. But, our household was very dysfunctional. ... I didn't have any adults that I trusted or had a good relationship with. My brother and I were not close anymore. I literally, I was just like, I don't have anybody to tell [about being raped]. ... One of the legacies of my childhood is that I have a really subpar emotional vocabulary ... Naming and identifying the emotions that I'm feeling, because we weren't really allowed to express the full spectrum of emotions growing up. It was this very middle ground. So, trying to identify the feelings that I'm feeling has ... always [been] a struggle for me.

Stephanie was not alone among the participants in experiencing major life traumas without emotional social support prior to becoming involved in white supremacy. Other participants discussed experiencing long-term hospitalizations, deaths of friends and family members, and long-term sexual abuse before they became white supremacists, citing no one available to help them process these emotional and physical traumas. As a result, they developed excessive anger that was reciprocated, and even encouraged, by members of white supremacist groups.

Such shared emotional energy fueled WST groups, which at times can be "positive" because they create and release pent up energy (Latif et al., 2018). Even if the emotions associated with the activities are negative (e.g., hatred and anger), the activities themselves cultivate a shared group energy as opposed to draining the energy of members. When considering differential social support theory, it appears that a lack of emotional support serves as a pull factor for people to engage in white supremacist terrorism. Thus, the shared emotional fervor of WST was attractive for 
participants because they craved the emotional support that came with it. Although the participants had different life experiences prior to engaging in WST, they all shared a desperate need for emotional support.

\section{During involvement: Shopping for hate}

Table 2 shows that eleven of the twelve participants were involved in multiple WST groups. Participants often explained that they shopped for the group whose ideology and behavior they found the least abrasive in the cultivation of emotional social support. The emotional support that participants received during their involvement was contingent on living a highly supervised, coercive, and isolated life. In other words, the support was toxic and aligned with Colvin and colleagues' (2004) differential social support. Over time, participants found the negativity of the emotional support their received from their involvement to be utterly exhausting, and they desired positive social support. Every participant in the sample experienced an increase of emotional support when they joined WST; however, it was greatly restrictive and toxic. Participants therefore had to "shop" for the WST group whose ideology they could tolerate the most easily, and often it took them several years before they fully adopted the ideology and found the best "fit."

Participants explained that as long as they were in a WST group, they were not given grief from their previous groups for switching to another group. This was because if they adopted an Aryan white supremacist ideology, it did not matter which faction they belonged to, because they were seen as being on the same side of the battle.

Moreover, participants described that it was common for certain groups to have reputations within the WST movement of offering different kinds of emotional support. Table 2 shows the typologies of these groups, according to participant descriptions. These typologies are not mutually exclusive, and Table 2 is not a complete list of WST groups in the US, UK, and Canada. Instead, it is a list of WST groups with which the participants had been involved. However, the typologies are classifications of what the groups offer and how they distinguish themselves from other groups within the WST movement. For a more complete review of WST groups, please see Simi and Futrell's (2015) American Swastika.

Table 2. Typologies of WST groups 


\begin{tabular}{|c|c|c|}
\hline Political & $\begin{array}{l}\text { Primarily focused on changing } \\
\text { legislation, electing public } \\
\text { officials, and holding political } \\
\text { conferences. }\end{array}$ & $\begin{array}{l}\text { National Socialist Movement, } \\
\text { British National Party, American } \\
\text { Nazi Party, Aryan Nations }\end{array}$ \\
\hline Religious & $\begin{array}{l}\text { Primarily focused on misusing } \\
\text { Christian doctrine to justify } \\
\text { WST views, lifestyles, and } \\
\text { violence. }\end{array}$ & Ku Klux Klan, Christian Identity \\
\hline Gang/White Power & $\begin{array}{l}\text { Primarily focused on using } \\
\text { ideology to justify violence, } \\
\text { partying, and listening to punk } \\
\text { and white power music. }\end{array}$ & $\begin{array}{l}\text { White Aryan Resistance, } \\
\text { Hammerskin Nation, Neo-Nazi } \\
\text { (various groups), Skinheads } \\
\text { (various groups) }\end{array}$ \\
\hline Terrorist & $\begin{array}{l}\text { Primarily focused on } \\
\text { international destruction and } \\
\text { mass violence to further WST } \\
\text { aims. }\end{array}$ & Combat 18, The Order \\
\hline
\end{tabular}

Along these typographical lines, it was quite common for participants to be highly critical of the WST groups they tried and rejected. For example, "Albert" - a former skinhead and neo-Nazi-explained why he did not join the KKK:

They're [Klanspeople] just a little weird with the Cyclops and the dragons and the pointed hats, and all that kind of stuff. And the Christian thing, I wasn't really...the Christian thing was a little bit off for me, because everything that they said, they always had some sort of biblical comparison. And it was just too much. So I just never really subscribed to their way of thinking.

This "shopping" process helped participants feel a sense of belonging once they had settled upon a group because it gave them a higher sense of autonomy. Oftentimes, participants were shopping for groups in terms of the emotional support they would receive from joining, as opposed to the beliefs the group espoused. For example, "Albert" described his decision to switch from one WST group to another:

I had been drinking quite heavily. And by this time, I probably had two DWIs, and I ended up quitting drinking. So there is a little bit of a positive thing out of my whole relationship with those people. And I haven't drank since. So, I think that's a good thing. ... So, I got involved with the Hammerskin Nation at that time, which 
a lot of us were starting to do that. Because the Hammerskin Nation was well known for being totally organized, very strict. There was no drugs involved, there was very little alcohol involved. And here I was, you know, recently sober doing the 12-step thing, but at the same time I was doing the political stuff. It just matched. And because of my being in the newspapers and the trial and everything that I was involved with, and doing time, I was sort of looked up to. At least that was what my perception was, is that I was looked up to.

Albert's quote exemplifies that although this overall support from Hammerskin Nation was negative, he believed it still initially had a positive impact on his life in terms of his sobriety. Emotional support was evident in Albert's quote because he described feeling that the group improved his self-esteem and gave him the impression that he was admired.

For many, involvement in WST offered some tangible benefits (e.g., romantic partners, housing, income, travel) while simultaneously exposing them to violence, radical ideological views, social isolation, and stigma. "John" described the emotional support he received from his former WST group during his incarceration:

People from the far right, they collected money for us, and they kept going round [to] make sure my mum and dad was all right [when I was in prison]. In that way that was like that, it was like having an extended family, you know? They really did look out for us. There's no doubt about it. I'd say probably when I was in the far right to be honest. It was ... You had a whole brotherhood and friends. There was always someone there for you.

John's statement demonstrates emotional support in that he felt looked after and that someone was always there for him despite being incarcerated.

Participants described their involvement in WST in ways consistent with Snow and Machalek's (1983) characteristics of converts as a social type. Participants described experiences consistent with biographical reconstruction, as they would cut ties with their pre-WST lives and only affiliate with other white supremacists. They often explained that over time they came to believe that the white race was under attack, and some experienced guilt that they were not involved sooner. For example, Rachel described that her choice to become a neo-Nazi was a direct rejection of her familial history: 
My parents were very upset. My father is an immigrant from England, and he grew up during World War II, and he spent his childhood in bomb shelters. And for his daughter to embrace national socialism after what happened to him and his family in the war was just beyond anything that he could cope with. He was just so upset.

Snow and Machalek's adoption of a master attribution scheme was pertinent to the lives of formers because although their WST groups were ideologically different, all of the groups believed in the 14 Words. The 14 Words is a common WST slogan coined by David Lane, a notorious WST who died while serving a 190-year prison sentence. The 14 Words are as follows, "We must secure the existence of our people and a future for white children." The 14 Words served as a master attribution scheme for participants during their involvement in WST, because although they were involved in different groups, all of the groups justified violence since they perceived that the white race was being attacked by perceived enemies and liberal agendas. "Lynn" explained the significance of the master attribution "1488" (i.e., symbolizing The 14 Words and Heil Hitler-as $\mathrm{H}$ is the eight letter of the alphabet), when she explained:

I got "1488" tattooed right across the side of my neck in old English lettering. That was to prove my commitment to myself and other people.

The suspension of analogical reasoning (Snow \& Machalek, 1983) is evident in participants' discussions of shopping for the right WST group and fiercely rejecting others, as opposed to seeing them as analogous. Participants described that they often used cognitive dissonance when they were involved in WST to ignore their own friendships and romantic relationships with perceived enemies. Several participants also noted that they remained in the movement despite questioning their sexualities and ultimately identifying as LGBTQ+ (since, non-heterosexual relationships are strictly prohibited in WST organizations). "Tracey" explained that although she was involved in the Klan, she never fully understood the racist ideology of the group. Instead, Tracey suspended her analytical reasoning in favor of group membership and social support:

If anything, I didn't share, I didn't share the hatred in my heart. I never understood the point of hating anybody just for the color of their skin. You know, but you go along to get along and when you're surrounded by that type.

Snow and Machalek's (1983) final criteria of converts is one's primary identity becoming their role in the group. Hank described this by stating, "It was who I was. It 
was what I listened to. It was what I wore. The clothes that I wore, the books that I read, the movies that I watched. It was where my social validation came from." Participants believed their lives did improve initially in all three areas of social support when they became involved in WST. The key benefits of initial involvement included a sense of belonging, brotherhood, camaraderie, friends, feeling understood, higher purpose, sense of family, protection, feeling important, feeling powerful, and words of affirmation-all examples of emotional support. However, over time they began to realize that they could once again change their lives to find social support that was not intertwined with hate, violence, and misinformation.

Stephanie explained her experience in wanting emotional support during her radicalization:

I didn't feel any personal value, but I felt like I could be of value to the movement. In fact, the more worthless I personally felt, the more I felt like my life could be given in value to the movement. ... I mean, I even had the conscious thought as I was radicalizing, as I was hanging out with these people that ... I had the conscious thought that I was just like, "Who the fuck is worse than the Nazi's? They have to take me in." Right?

Multiple participants echoed Stephanie's sentiment and explained that it was attractive to them that the groups they joined were highly stigmatized because it increased their odds of being accepted by the group, and they believed they were less likely to be bullied or harassed by non-members because those people would fear them. Many participants explained that they felt powerful adrenaline rushes from knowing that they were actively feared by non-members in their communities. This dichotomy of having emotional support from the group at the expense of social stigma and fear from broader society wore on participants over time, and they questioned the worth of the relationships they once felt to be so important. This is consistent with Paternoster and Bushway's (2009) ITD which explains that people continue criminal involvement when they perceive it as ultimately beneficial; however, as they begin to fear the consequences of remaining involved, their identities shift, and they begin the process of desisting. In hindsight, John reevaluated the friendships he had during his involvement:

Because when you're involved, that's 15 years of my life that was just filled with violence, negativity, toxic. Like every bad thing you can think of. There's nothing positive. Well I say nothing positive, I did have friends, but are they really friends if they're just friends because you're in the same group as them? Is that a real 
friend? Just that negativity, and not just for me. The negativity I put out in the world as well. The way I'd talk to people and just look at people like they was nothing, that I was better than them. Yes, just horrible that was.

On Figure 1, between "during involvement" and "exiting," there is a green dashed circle which represents "the big choice" that my participants described when they began thinking about leaving WST. The big choice is the decision to give up all social support-because it is negative-in the hopes that one will be able to rebuild their life and eventually find positive emotional support. Participants postulated that many of the people who exited, and ultimately rejoined WST, did so because the lack of emotional support during exiting was too much for some to bear. Emma similarly expressed the belief that social support within WST was negative and forced her to make the "big choice" when she was deciding to exit:

So on the one hand, you have kind of like a big community, but on the other hand it's very isolating which is part of why I had a lot of trouble making friends when I got out 'cause I had to pretty much leave everything behind. I had to start over from nothing.

Participants facing the big choice must prepare themselves to completely abandon their social networks and identities and accept that they will likely have a long period of time before they rebuild social support in their lives again. Many participants expressed that the big choice was daunting because they did not believe that they ever could be accepted or integrated back into mainstream society because of their WST pasts. The toxic emotional support formers received while involved was contingent on them obeying rigid rules, with dire consequences if not followed. Moreover, it was all intended to make them better soldiers and procreators for the white race, as opposed to their personal growth.

\section{Exiting: Hate exhaustion}

Participants explained that they often had no personal avenues of emotional support, and thus, they relied on charity organizations-usually homeless shelters-to fully disengage from WST. "Rachel” explained that her exit from WST was so difficult that she contemplated suicide:

The drawbacks unfortunately were quite substantial. I had trouble getting housing. Nobody wanted to rent to me the notorious Heritage Front member. It was very hard to find roommates. ... I ended up just feeling emotionally just completely burnt out. ... And I just couldn't cope with that anymore. I needed 
some space. So yeah, my mental health took a serious hit. I was very, very lost and I never attempted suicide, but I was certainly suicidal. I ended up in crisis center[s] a few times and I mean it was really hard. I don't regret leaving, but at the same time, I'm glad I won't have to go through that ever again. So it was really a difficult time.

Participants described three key themes that emerged as they attempted to exit WST: ideological doubts, emotional exhaustion, and positive experiences with people of color. These themes often overlapped and reinforced one another. Participants typically described feeling emotionally exhausted from living in a highly coercive environment, having a positive experience with a person of color which temporarily relieved their emotional exhaustion, and that experience fueling ideological disillusionment with the idea that people of color are threats to the white race. Emotional exhaustion fits within Paternoster and Bushway's (2009, p. 1108) explanation of ITD in that, "the decision to quit crime [is] just that-a decision by an offender that she has 'had enough' of crime and being a criminal and desires a change in what she does and who she is." Citing Baumeister (1994), Paternoster and Bushway (2009) call this process of increasing solidification of dissatisfaction with a criminal lifestyle as the crystallization of discontent. This study found that participants left WST when their ideological doubts, hate exhaustion, and positive experiences with people of color led them to wish for a more prosocial identity, in a process that absolutely exemplifies this concept.

Participants often spoke about emotional exhaustion stemming from the stringent restrictions placed upon them by the group: needing to only listen to white power music, dress in clothing to denote group membership, avoid eating Kosher foods, and never have positive (or even neutral) interactions with perceived enemies (e.g., people of color, LGBT+ folks, Jews, etc.). Moreover, the norms associated with punishing disobedient WSTs were severe and encompassed examples of toxic emotional support. For example, Lynn, a former WST, explained that she was jumped by four members of her WST group when she was involved because she was suspected of becoming an antifascist because of her behavior. The assault was traumatic and physically disabling, as she attested it took months of physiotherapy for her to regain basic functioning. Lynn's experience is an example of toxic support, because her assault was seen as tough love and an effort by group members to keep her from leaving the group.

This idea is consistent with Latif and colleagues' (2018) Trajectory of Decline model, which posits that non-shared emotions lead to identity turmoil for individuals and social friction within the group, which predicate people's exits from white supremacist 
groups. The big choice encompasses both concepts, underscoring that the decision to exit WST is one that involves leaving toxic emotional support in exchange for uncertain support moving forward. Participants made the big choice because the social support given by their WST groups was contingent on social isolation and hatred, both of them involving high levels of emotional work which was difficult to sustain. This finding directly relates to Hochschild's (1979, p. 551) concept of emotional management, "the type of work it takes to cope with feeling rules." Feeling rules refers to the formal and informal expectations of emotional expressions regulated by an ideology (Hochschild, 1979).

Most of the research on emotional work and management refers to employees being required to express positive emotions that they do not feel (e.g., nurses remaining positive for patients in dire situations); however, scholars have found that emotional labor manifests into burnout (Jeung et al., 2018). Formers explained that they felt emotionally exhausted from the emotional labor of having to present as hateful when they did not fully subscribe-or were beginning to doubt-their groups' ideologies. This emotional exhaustion seems to mirror the relationship between emotional work and occupational burnout, as in many ways, involvement in WST was much like a job. In other words, exit enabled participants to search for healthier, more positive, and less conditional emotional social support.

Steve described that he struggled to maintain an anti-Semitic ideology when he received medical treatment from a Jewish doctor:

We had gotten in this big melee with these Vietnamese folks, and I was laying on the table in the hospital and I was wearing a swastika shirt and all this, and this Orthodox Jewish doctor walked in. So when I look back onto my life, I usually think about that moment. It was so elemental to me because he said not one thing about my politics or who I was, all he did was come in and treat me like a human being and helped me. So, when I look back on, like we've been talking about not really believing in the ideology or like it took a while to get there, probably because I didn't. Right? Like really inside me, it's a struggle to believe in Nazism. It's a pretty hard thing. But when I think about that moment, I just think about that particular human being's compassion and how he treated me. Which was like you can't replace that with anything else.

Steve's excerpt demonstrates that although he was receiving emotional support from the doctor who was providing him with medical care, this support was temporary. Nearly every participant expressed that while they were exiting, they had a positive 
experience with a person considered an "enemy" by their previous WST group. Another such example is that of "Vince" who-while exiting-rented an apartment from a Turkish Muslim man whom he befriended over time:

And just over a time period of let's say six months interacting with a Muslim, just showed me some respect and compassion that I thought I didn't deserve it. ... He even asked me to repair his computer and paid me for some time, and started putting food there, Turkish food which at first I didn't want to touch, but I just ate it because I didn't want to test out how offended he may be if I don't. And it became just normal, more normal, more normal, just wasn't normal to me. At some point I didn't take the money anymore and at the end I was just waiting for him to rip off the mask and show his true face, the Muslim terrorists, that ugly guy. And I just realized I was the ugly guy; I was the one expecting these stereotypes to happen and that just showed me even more how wrong I was. How good it was that I separated from those groups. That I have to explore, actually this world out there more.

Although these experiences comprised instances of emotional support, they were brief and rare; the continuous support that they had received while involved in WST took years to replace after exiting. Essentially, once participants left their former WST groups, they were completely shunned by the group, and often threatened. Moreover, because of their previous identification-and often appearances-participants were also shunned from mainstream society. Participants described struggling to find jobs and housing after exit from WST because often they still had swastika, 1488, and Hitler tattoos. It was not until participants had fully disengaged from WST that they were able to cultivate emotional support from positive and stable sources.

\section{After exit: Relief and emotional support}

This study finds that after completely severing ties with WST, participants were able to find positive and stable emotional support from new sources. All 12 former WST participants concurred that they had the most positive, highest quality support in their lives at the times of their interviews. Eleven of them agreed that they also had more sources of emotional support (e.g., friends, family, religious organizations, non-profit organizations, etc.) at the present than at any other time in their lives. The one dissenting participant explained that he felt that he had more people he could turn to when he was involved in WST but that the support he received was largely negative. Of note, this participant had exited from WST the most recently of all of the participants, being out only six months prior to the interview. 
There was a clear consensus among participants that there was a need for more emotional support during the exiting process, because their lives had become much more fulfilling after leaving WST. Almost all of the participants currently volunteer or work in countering violent extremism and/or anti-racist activism. A common sentiment shared by all the participants was that they wanted to tell people who are still involved or who are leaving WST that their lives improved upon leaving and wished they had left earlier. Thus, not simply receiving emotional support, but providing it in return, was important for participants in making meaning out of their experiences as formers and finding new direction. This is consistent with Paternoster and Bushway's (2009) ITD, which maintains that prosocial roles are only maintained after someone's identity as a criminal has changed. When asked about the positive aspects of life post-exit, Tracey explained:

Getting the truth out and healing. Like I say, the relationship I'm in, very healthy, very much love, much respect going both ways and my children. My children are my greatest joy. My children are my reason for being and they are the best part of me and honestly, I don't know, I have no idea how it is that somebody can bring children into this world and not love them. I mean, because my children are my everything. They saved my life.

Ten of the participants talked about finding healthy and supportive romantic relationships after leaving WST. Of these ten participants, eight had partners with no involvement at any time with WST. For the two participants whose partners had also been in WST, both partners had also exited. Leaving WST often helped participants reconnect with family members and/or start families of their own. One participant, "Lynn," explained that she was able to reconnect with her mother and found social support from Life After Hate, an organization that provides resources for people leaving White supremacy:

Pretty much everyone around me. I can talk to anybody in Life After Hate about anything I want, even if it's not movement-related whatsoever. My mom and I get along really good now. We're actually doing our own independent project together.

Moreover, participants agreed that the greatest benefit from leaving WST was the relief from no longer living in a hateful and controlling environment, and as a result they experienced a new sense of freedom. Rachel explained,

The immediate benefits were that I would free up these hateful toxic people, that I wasn't being pressured anymore to be doing activities and saying things that were 
hurting other people. I mean that was definitely a benefit.

This speaks to the tremendous burden that hate exhaustion takes on participants, and the need to emotionally support people leaving WST. Indeed, formers enjoyed the increase in autonomy over their lives and took comfort in the day-to-day living routines with their families. Steve articulated this idea:

Wife, kids, living that life of the day-to-day as much as that sounds super boring, it's like ... Just the difference of not having to worry about going to your car in the morning and worried about the gang stuff, all of that. I mean, the groups that I was in, it took a lot of your mental time dealing with the ins and out of all that business rather than this present day, you have to think about real things, which can be stressful too but we all know that we have to deal with those things, right? Whether it's bills or your house or cutting the lawn or whatever, it's a lot easier to deal with that than, "Gee, I wonder if so-and-so is going to come and I wonder if there's going to be violence today. I wonder if there's going to be cops today." All of those things were pretty stressful, so it's nice to live without those things now.

Every participant echoed Steve's belief in that they felt that their experiences joining and exiting WST gave them unique perspectives on life that improved their resilience during life's challenges. Participants felt self-efficacy in making their lives positive through giving and receiving emotional social support.

\section{Conclusion}

The findings of this research indicate that people who have departed violent extremist White supremacist groups have a pattern regarding differential emotional support that links them all. The general pattern this research found was that former White supremacists began with a deficit in emotional support prior to extremist involvement. Participants expressed deficits in emotional social support prior to WST affiliation. Many explained that they got involved to obtain emotional support and became radicalized after the fact. It is important to note that participants found that emotional support was more important to them than ideology when selecting WST groups. This finding is significant because it is contrary to the notion that people join White supremacist groups after they have already been radicalized. In contrast, my findings underscore that radicalization only happened for certain participants and occurred because they were unwilling to relinquish the emotional support they found within White supremacism. 
Formers received toxic emotional support during their WST involvement that was highly coercive and isolated them from all people who were not White supremacists. Over time, usually over the course of many years, participants began to desire (and think it was possible) for them to find non-coercive emotional support. But this prospect was risky since it was at the expense of giving up the only consistent social support many of them had ever had. Nearly all of the participants remarked that the coercion they experienced in the movement could not be compensated for by the emotional support they received from it, and they experienced "hate exhaustion" which prompted their disengagement and for many, their deradicalization. All the participants explained that the most difficult challenge of leaving the White supremacist movement was not the residual ideological effects, but rather the complete abandonment of emotional support after experiencing consistent coercion for many years.

These findings have both conceptual and pragmatic contributions. In Figure 1, I outline the relevance of emotional support throughout engagement and exit from WST that is described in supported former White supremacists' experiences. Similarly, this study's findings support Colvin and colleagues' (2002) model of differential social support and coercion by serving as an example of how differential emotional support pulls people into and out of WST. Furthering Latif and colleagues' (2018) emotional dynamics model, my findings illustrate the pivotal role of emotional social support-as vital to understand White supremacist group dynamics and why people chose to exit WST. This research supports the notion that former WSTs are converts as described by Snow and Malachek (1983). This work defined hate exhaustion and demonstrated that it is a catalyst for exiting WST. The findings give mixed support for Paternoster and Bushway's (2009) ITD. The notion of a 'feared self' was not a key motivating factor for desistance from WST; however, constructing a prosocial identity was.

\section{Study limitations}

This study has several limitations. Due to resource restrictions, most interviews were conducted via telephone as opposed to in-person, which means that facial expressions and body language were largely not included in the data. Further, formers are a highly stigmatized and hard to reach population; therefore, the sample size was small. This study is cross-sectional rather than longitudinal. Although I cannot track emotions and social support as they vary across time, I rely on participants' recollections and verified this information with them once more after their interviews. Despite these limitations, the participants were incredibly generous with the information they were 
willing to provide and thus, the data that were collected were full of thick descriptions. Future research should explore the nuances of hate exhaustion, the effectiveness of different programs seeking to rehabilitate formers, and other groups in which the Former White Supremacists Emotional Support Model (Figure 1) may apply. A closer inquiry into the roles that social networks and social capital play, into and out of violent extremism, would enhance both the scholarship on terrorism and national security efforts. I intend to further study multiple violent extremist groups and the "shopping" processes that are used to engage in terrorism.

\section{Implications}

On a pragmatic note, this research emphasizes the importance of providing emotional support to people so that they can leave WST or prevent them from joining in the first place. Many participants recalled a teacher from their childhood or adolescence-as the only source of support prior to WST - that had a positive impact on their life or that they wish they had listened to earlier. It may be helpful to educate teachers about White supremacist terrorism and their role in preventing it. This study posits that programs that provide resources for those transitioning out of WST are useful and effective because they increase the emotional support that highly stigmatized and isolated people need to become formers. These programs help people recuperate from hate exhaustion by creating support networks of people who have experience overcoming and managing it. Such programs include but are not limited to: Life After Hate, The Free Radicals Project, The Forgiveness Project, and Parallel Networks.

\section{References}

Aresti, A., Eatough, V., \& Brooks-Gordon, B. (2010). Doing time after time: An interpretative phenomenological analysis of reformed ex-prisoners' experiences of selfchange, identity and career opportunities. Psychology, Crime \& Law, 16(3), 169-190. https://doi.org/10.1080/10683160802516273

Bachman, R., Kerrison, E., Paternoster, R., Smith, L., \& O'Connell, D. (2016a). The complex relationship between motherhood and desistance. Women \& Criminal Justice, 26(3), 212-231. https://doi.org/10.1080/08974454.2015.1113153

Bachman, R., Kerrison, E., Paternoster, R., Smith, L., \& O’Connell, D. (2016b). Desistance for a long-term drug-involved sample of adult offenders. Criminal Justice and Behavior, 43(2), 164-186. https://doi.org/10.1177/0093854815604012 
Baumeister, R. F. (1994). The crystallization of discontent in the process of major life change. In T. F. Heatherton \& J. L. Weinberger (Eds.), Can personality change? (pp. 281-297). American Psychological Association.

Blee, K. M. (2002). Inside organized racism: Women in the hate movement. University of California Press.

Blee, K. M. (2005). Women and organized racial terrorism in the United States. Studies in Conflict \& Terrorism, 28(5), 421-433. https://doi.org/10.1080/10576100500180303

Bubolz, B. F., \& Simi, P. (2015). Leaving the world of hate: Life-course transitions and self-change. American Behavioral Scientist, 59(12), 1588-1608.

https://doi.org/10.1177/0002764215588814

Brezina, T., \& Azimi, A. M. (2018). Social support, loyalty to delinquent peers, and offending: An elaboration and test of the differential social support hypothesis. Deviant Behavior, 39(5), 648-663. https://doi.org/10.1080/01639625.2017.1286190

Carson, D. C., \& Vecchio, J. M. (2015). Leaving the gang: A review and thoughts on future research. In S. H. Decker \& D. C. Pyrooz (Eds.), The handbook of gangs (pp. 257-275). John Wiley \& Sons, Inc.

Colvin, M., Cullen, F. T., \& Vander Ven, T. (2002). Coercion, social support, and crime: An emerging theoretical consensus. Criminology, 40(1), 19-42.

https://doi.org/10.1111/j.1745-9125.2002.tb00948.x

Collins, R. (2004). Interaction ritual chains. Princeton University Press.

Cullen, F. T. (1994). Social support as an organizing concept for criminology: Presidential address to the academy of criminal justice sciences. Justice Quarterly, 11(4), 527-559. https://doi.org/10.1080/07418829400092421

Decker, S. H., \& Lauritsen, J. L. (2002). Leaving the gang. Gangs in America , 3, 51-70. https://doi.org/10.4135/9781452232201.n4

Densley, J. A., \& Pyrooz, D. C. (2019). A signaling perspective on disengagement from gangs. Justice Quarterly, 36(1), 268-283. https://doi.org/10.1080/07418825.2017.1357743

Gramling, L. F., \& Carr, R. L. (2004). Lifelines. Nursing Research, 53(3), 207-210. https://doi.org/10.1097/00006199-200405000-00008 
Hightower, E. (1997). Psychosocial characteristics of subtle and blatant racists as compared to tolerant individuals. Journal of Clinical Psychology, 53(4), 369-374. https://doi.org/10.1002/(sici)1097-4679(199706)53:4<369::aid-jclp10>3.0.co;2-e

Hochschild, A. R. (1979). Emotion work, feeling rules, and social structure. American Journal of Sociology, 85(3), 551-575. https://doi.org/10.1086/227049

Horgan, J. G. (2009). Walking away from terrorism: Accounts of disengagement from radical and extremist movements. Routledge.

House, J. S., Umberson, D., \& Landis, K. R. (1988). Structures and processes of social support. Annual Review of Sociology, 14(1), 293-318.

https://doi.org/10.1146/annurev.so.14.080188.001453

Jayaratne, S., \& Chess, W. A. (1984). The effects of emotional support on perceived job stress and strain. The Journal of Applied Behavioral Science, 20(2), 141-153. https://doi.org/10.1177/002188638402000205

Jeung, D. Y., Kim, C., \& Chang, S. J. (2018). Emotional labor and burnout: A review of the literature. Yonsei medical journal, 59(2), 187-193.

https://doi.org/10.3349/ymj.2018.59.2.187

Kruglanski, A. W., Gelfand, M. J., Bélanger, J. J., Sheveland, A., Hetiarachchi, M., \& Gunaratna, R. (2014). The psychology of radicalization and deradicalization: How significance quest impacts violent extremism. Political Psychology, 35(1), 69-93. https://doi.org/10.1111/pops.12163

Latif, M., Blee, K., DeMichele, M., \& Simi, P. (2018). How emotional dynamics maintain and destroy white supremacist groups. Humanity \& Society, 42(4), 480-501. https://doi.org/10.1177/0160597618802552

LeBel, T. P., Burnett, R., Maruna, S., \& Bushway, S. (2008). The `chicken and egg' of subjective and social factors in desistance from crime. European Journal of Criminology, 5(2), 131-159. https://doi.org/10.1177/1477370807087640

Maruna, S. (2001). Making good: How ex-convicts reform and rebuild their lives. American Psychological Association.

Moule, R. K., \& Pyrooz, D. C. (2014). Social capital, the life-course, and gangs. In C. L. Gibson \& M. D. Krohn (Eds.), Handbook of life-course criminology: Emerging trends and directions for future research (pp. 143-158). Springer. 
Paternoster, R., \& Bushway, S. (2009). Desistance and the "feared self": Toward an identity theory of criminal desistance. The Journal of Criminal Law and Criminology, 99(4), 1103-1156.

Paternoster, R., Bachman, R., Kerrison, E., O’Connell, D., \& Smith, L. (2016).

Desistance from crime and identity: An empirical test with survival time. Criminal Justice and Behavior, 43(9), 1204-1224. https://doi.org/10.1177/0093854816651905

Pyrooz, D. C., Decker, S. H., \& Webb, V. J. (2010). The ties that bind: Desistance from gangs. Crime \& Delinquency, 60(4), 491-516.

https://doi.org/10.1177/0011128710372191

Pyrooz, D. C., \& Decker, S. H. (2011). Motives and methods for leaving the gang: Understanding the process of gang desistance. Journal of Criminal Justice, 39, 417425. https://doi.org/10.1016/j.jcrimjus.2011.07.001

Raets, S. (2019). Desistance, disengagement and deradicalization: How the research on quitting crime can inform the study of leaving violent extremism behind. In ConverGENT: Convergent roads, bridges and new pathways in criminology : 19th Annual Conference of the European Society of Criminology (EUROCRIM 2019).

Reid, S. E., \& Matthew, V. (2020). Alt-right gangs: A hazy shade of white. University of California Press.

Roman, C. G., Cahill, M., \& Mayes, L. R. (2021). Changes in personal social networks across individuals leaving their street gang: Just what are youth leaving behind? Social Sciences, 10(2), 39. https://doi.org/10.3390/socsci10020039

Sampson, R. J., \& Laub, J. H. (2003). Life-course desisters? Trajectories of crime among delinquent boys followed to age 70. Criminology, 41(3), 555-592.

https://doi.org/10.1111/j.1745-9125.2003.tb00997.x

Simi, P. (2010). Why study white supremacist terror? A research note. Deviant Behavior, 31(3), 251-273. https://doi.org/10.1080/01639620903004572

Simi, P., Blee, K., DeMichele, M., \& Windisch, S. (2017). Addicted to hate: Identity residual among former white supremacists. American Sociological Review, 82(6), 11671187. https://doi.org/10.1177/0003122417728719

Simi, P., \& Futrell, R. (2015). American swastika: Inside the white power movement's hidden spaces of hate. Rowman \& Littlefield. 
Snow, D. A., \& Machalek, R. (1983). The convert as a social type. Sociological Theory, 1, 259-289. https://doi.org/10.2307/202053

Stone, R. (2016). Desistance and identity repair: Redemption narratives as resistance to stigma. British Journal of Criminology, 56(5), 956-975.

Umberson, D., \& Karas Montez, J. (2010). Social relationships and health: A flashpoint for health policy. Journal of Health and Social Behavior, 51(1), S54-S66.

https://doi.org/10.1177/0022146510383501

Windisch, S., Simi, P., Ligon, G. S., \& McNeel, H. (2016). Disengagement from ideologically-based and violent organizations: A systematic review of the literature. Journal for Deradicalization, 9, 1-38.

\section{Contributor}

April Gould received her B.A. in public health policy from UC Irvine and her M.P.H. from the University of Virginia. She is currently pursuing a Ph.D. in Sociologyconcentrating on criminology and medical sociology-at the University of California, Riverside. She has published on risk assessments for terrorists, child abductionmurders, and juvenile competence attainment.

\section{Reviews}

